\title{
4. Hurricanes and coastlines: The role of natural disasters in the speciation of howler monkeys
}

\author{
Alison M Behie, Travis S Steffens, Tracy M Wyman, \\ Mary SM Pavelka
}

In his highly influential book Primate Taxonomy, Colin Groves discusses the importance of having an accurate account of primate taxa in order to understand evolutionary relationships that exist between species. This includes understanding genetic and morphological similarities between species as well as the processes of speciation. As the most widely ranging Neotropical monkey, the evolutionary relationships of the genus Alouatta have been examined from behavioural, morphological and most recently genetic data. According to Groves (2001) there are nine or 10 species of Alouatta and up to 19 subspecies (Table 4.1). Of these species, three are found in Mesoamerica: A. palliata, A. pigra and A. coibensis, with the rest located in South America. However, a more recent study of the molecular genetics of these species revealed $A$. coibensis to be indistinct from $A$. palliata, leaving $A$. pigra and $A$. palliata as the two remaining species in the Mesoamerican clade of howlers (Cortes-Ortiz et al., 2003). In 2012, while at a conference in Mexico, the lead author asked Colin what his thoughts were on the potential role of severe weather in speciation events, and more specifically on the biogeographical distribution on these two closely related species. He admitted he had never given it much thought, but was intrigued by the idea. This chapter further investigates this idea, by pulling together an array of evidence for both $A$. pigra and $A$. palliata in an attempt to add another piece to the puzzle of what factors are important in defining species.

Until 1970 A. pigra was considered a subspecies of $A$. palliata, when they were separated into two distinct species by Smith. This distinction was based on differences in their cranial size and morphology, characteristics of the upper molar dentition as well as the colour and texture of the pelage. Horwich and Johnson (1986) later noted that testes descend much earlier in A. pigra, and that $A$. pigra lives in consistently smaller social groups. The taxnomonic separation of A. pigra and A. palliata was genetically confirmed by Cores-Ortiz and others (2007) who showed them to have a $5.7 \%$ difference in mitochondrial DNA. 
Taxonomic Tapestries

Table 4.1: Howler species (genus Alouatta) as recognised by Colin Groves in Primate Taxonomy (2001).

\begin{tabular}{|c|c|c|}
\hline \multicolumn{3}{|l|}{ Alouatta palliata group } \\
\hline & \multicolumn{2}{|l|}{ Alouatta palliata } \\
\hline & \multicolumn{2}{|l|}{ Alouatta pigra } \\
\hline & \multicolumn{2}{|l|}{ Alouatta coibensis } \\
\hline \multicolumn{3}{|c|}{ Alouatta seniculus group } \\
\hline \multicolumn{3}{|c|}{ Alouatta seniculus } \\
\hline & & Alouatta seniculus arctoidea \\
\hline & & Alouatta seniculus juara \\
\hline \multicolumn{3}{|c|}{ Alouatta macconnelli } \\
\hline \multicolumn{3}{|c|}{ Alouatta sara } \\
\hline \multicolumn{3}{|c|}{ Alouatta belzebul } \\
\hline & \multicolumn{2}{|l|}{ Alouatta nigerrima } \\
\hline & \multicolumn{2}{|l|}{ Alouatta guariba } \\
\hline & & Alouatta guariba guariba \\
\hline & & Alouatta guariba clamitans \\
\hline \multicolumn{3}{|l|}{ Alouatta caraya group } \\
\hline \multicolumn{3}{|c|}{ Alouatta caraya } \\
\hline
\end{tabular}

Note: This chapter considers only the first group, which is the Central American group.

Source: After Groves (2001).

The dominant view of the colonisation of Mesoamerica by South American primate species revolves around the barrier created by the Andes, which limited the ability of taxa to move out of South America (Ford, 2006). When a land bridge formed between the two regions 3.5 million years ago, the only genera that were able to migrate were those already across this boundary in the northwest of South America. This included the genera Alouatta, Ateles, Aotus, Cebus and Saguinus. The divergence of the Mesoamerican Alouatta species into $A$. pigra and $A$. palliata could have occurred in one of two ways: colonisation by a single species that later split or speciation pre-colonisation and a first wave of A. pigra followed later by A. palliata (Smith, 1970). Cores-Ortiz and others' (2007) genetic data suggest a split of three million years ago for the two species, which coincides with the formation of the Panamanian land bridge. This is consistent with either the pre or post colonisation split. Ford (2006) supports a pre-colonisation speciation followed by four to five waves after the formation of the land bridge, however, cautions that due to the poorly resolved phylogenies of Mesoamerican primate species, the data do not support firm conclusions about this.

It has been suggested that $A$. palliata may not have been able to colonise areas where $A$. pigra are found due to the ability of $A$. pigra to live in a wider range of habitat types including swamps, mangroves and dry deciduous forests (Reid, 
1997). Further, A. pigra is mainly found in lowland coastal regions of less than $500 \mathrm{~m}$ (Horwich and Johnson, 1986; Baumgarten, 2006). Coastal forests of low elevation have an increased vulnerability to storms and severe stochastic weather patterns (Ford, 2006). As part of the Northern Atlantic Cyclone Basin, the Caribbean along with Central and South America are frequently hit by hurricanes, averaging six hurricanes and two tropical storms per year (www.noaa.com). Most of these, however, pass through the northern part of the hurricane basin in the Yucatan region. This type of regular exposure to severe weather events should have profound effects on the animals living in the area and, depending on frequency of exposure, could have influenced their behaviour and demographic profile (Ford, 2006). This is certainly the case in Madagascar, where the history of regular cyclones has resulted in changes to lemur behaviour and morphology including, small group size, high degrees of energy conserving behaviours (including torpor), and a limited number of species that are dedicated frugivores (Wright, 1999).

In this chapter we explore the possible role of severe weather events in determining the biogeographical distribution of A. pigra and A. palliata through a study of the forest characteristics that predict the occurrence of $A$. pigra in Belize. We also conduct an examination of group size and evidence of energy conservation in A. pigra and A. palliata to determine if $A$. pigra show any of the behavioural features associated with living in a stochastic environment. Finally we look for evidence of different levels of environmental stochasticity faced by $A$. pigra as compared to $A$. palliata by comparing the frequency of hurricanes and other tropical storms making landfall in the regions populated by each species. While we acknowledge that Colin Groves considers $A$. coibensis a separate species (Table 4.1), in this paper we focus on A. palliata and A. pigra due to limited data available on $A$. coibensis as well as the fact that its distribution is limited to the island of Coiba, which is located outside of a hurricane belt (Rylands et al., 2006).

\section{Materials and methods}

\section{Forest characteristics associated with A. pigra}

We used satellite imagery, local informants, guides, and published literature to identify areas that might contain $A$. pigra populations or be suitable habitat for A. pigra in Belize. To determine A. pigra presence or absence, and relative abundance, areas that were accessible were surveyed on foot using existing trails, logging roads, new trails or by boat along rivers. When a group of $A$. pigra was spotted, location data were collected using a hand held Global Positioning System device (Garmin GPSmap 60CSx). When possible this included the exact location of the 
group, but when it was not possible we recorded our location and a compass bearing towards the group and a visual estimate of the distance to the group in metres. We also recorded the group size and composition, height in the canopy and group activity. When a group was heard vocalising we estimated the distance in metres and direction of the group. In previous studies (Pavelka et al., 2007), we found this overestimated the distance by 0.5 to $1.0 \mathrm{~km}$, therefore we took this into account in our analysis here. All spatial data (visual and vocal contacts, confirmations of presence from local informants, and track information) were entered into ArcMap software (v.10.1). Relative abundance was calculated by dividing the number of monkeys sighted by the total distance $(\mathrm{km})$ walked, in that patch.

To assess forest characteristics associated with $A$. pigra, we measured its presence or absence and relative abundance in relation to anthropogenic disturbance (road density, number of settlements, human population density, amount of edge, and presence of agriculture), natural disturbance (hurricanes), and patch characteristics (patch size, patch type, river density, and elevation). We used ArcMap GIS (v.10.1) software to measure road density, the number of settlements within a patch, human population density of the patch, amount of edge to area ratio of a patch, how many hurricanes of category 1-4 have occurred within a patch, patch size, patch type, river density, and mean area-weighted patch elevation. The data to measure the above variables were acquired from BERDS (Biodiversity and Environmental Resource Data System) for all variables except the number of hurricanes, which was acquired from the National Oceanic and Atmospheric Administration (NOAA, 2006).

\section{Behavioural comparisons between $A$. pigra and $A$. palliata}

We surveyed the available literature on A. pigra and A. palliata to determine the average and mean group size of each species as well as to determine the influence of fruit consumption on activity budgets to look for indications of energy minimising behaviour. For the behavioural studies, we only included studies that were done over greater than six months to allow for seasonal variation in fruit availability and consumption to be considered. This resulted in the inclusion of three studies for A. pigra and 13 for A. palliata (Table 4.2). Due to this limited sample size, no statistical analyses could be performed on the behavioural changes associated with seasonal fruit scarcity, however, these data were compared qualitatively. 
Table 4.2: Studies included in behavioural comparisons of Alouatta pigra and $A$. palliata.

\begin{tabular}{|c|c|c|c|c|}
\hline $\begin{array}{c}\text { Behavioural response } \\
\text { to fruit shortage }\end{array}$ & Species & Study site & $\begin{array}{c}\text { Group size } \\
\text { (\# individuals) }\end{array}$ & Reference \\
\hline \multirow[t]{4}{*}{$\begin{array}{l}\text { Decrease time spent } \\
\text { travelling/ranging }\end{array}$} & $\begin{array}{l}\text { Alouatta } \\
\text { palliata }\end{array}$ & $\begin{array}{l}\text { Los Tuxlas, } \\
\text { Mexico }\end{array}$ & 14 & Estrada, 1984 \\
\hline & & $\begin{array}{l}\text { Arroyo Liza, } \\
\text { Mexico }\end{array}$ & 6 & Asensio et al., 2007 \\
\hline & $\begin{array}{l}\text { Alouatta } \\
\text { pigra }\end{array}$ & Monkey River & 6.6 & $\begin{array}{l}\text { Pavelka and Knopff, } \\
2004\end{array}$ \\
\hline & & $\begin{array}{l}\text { Cockscomb } \\
\text { Basin Wildlife } \\
\text { Sanctuary, Belize }\end{array}$ & 6.5 & $\begin{array}{l}\text { Silver and Marsh, } \\
2003\end{array}$ \\
\hline Group fission & $\begin{array}{l}\text { Alouatta } \\
\text { palliata }\end{array}$ & $\begin{array}{l}\text { Agaltepec Island, } \\
\text { Mexico }\end{array}$ & 59 & Asensio et al., 2007 \\
\hline \multirow[t]{2}{*}{$\begin{array}{l}\text { Increase time spent } \\
\text { feeding }\end{array}$} & $\begin{array}{l}\text { Alouatta } \\
\text { palliata }\end{array}$ & $\begin{array}{l}\text { Los Tuxlas, } \\
\text { Mexico }\end{array}$ & 4 & $\begin{array}{l}\text { Sheddon-Gonzalez } \\
\text { and Rodriguez-Luna, } \\
2010\end{array}$ \\
\hline & & $\begin{array}{l}\text { La Pacifica, } \\
\text { Costa Rica }\end{array}$ & 13 & Glander 1978 \\
\hline \multirow[t]{7}{*}{$\begin{array}{l}\text { Increased time spent } \\
\text { travelling/ranging }\end{array}$} & $\begin{array}{l}\text { Alouatta } \\
\text { palliata }\end{array}$ & $\begin{array}{l}\text { La Pacifica, } \\
\text { Costa Rica }\end{array}$ & 25 & $\begin{array}{l}\text { Williams-Guillen, } \\
2003\end{array}$ \\
\hline & & $\begin{array}{l}\text { La Pacifica, } \\
\text { Costa Rica }\end{array}$ & 15 & $\begin{array}{l}\text { Williams-Guillen, } \\
2003\end{array}$ \\
\hline & & $\begin{array}{l}\text { La Pacifica, } \\
\text { Costa Rica }\end{array}$ & 20 & $\begin{array}{l}\text { Williams-Guillen, } \\
2003\end{array}$ \\
\hline & & $\begin{array}{l}\text { La Pacifica, } \\
\text { Costa Rica }\end{array}$ & 13 & Glander, 1978 \\
\hline & & $\begin{array}{l}\text { Agaltepec Island, } \\
\text { Mexico }\end{array}$ & 10 & $\begin{array}{l}\text { Rodriguez Luna et } \\
\text { al., } 2003\end{array}$ \\
\hline & & $\begin{array}{l}\text { Agaltepec Island, } \\
\text { Mexico }\end{array}$ & 27 & $\begin{array}{l}\text { Rodriguez Luna et } \\
\text { al., } 2003\end{array}$ \\
\hline & & $\begin{array}{l}\text { Barro Colorado } \\
\text { Island, Panama }\end{array}$ & & Milton, 1980, 1981 \\
\hline \multirow[t]{6}{*}{$\begin{array}{l}\text { No change in } \\
\text { behaviour }\end{array}$} & $\begin{array}{l}\text { Alouatta } \\
\text { palliata }\end{array}$ & $\begin{array}{l}\text { Los Tuxlas, } \\
\text { Mexico }\end{array}$ & 7 & $\begin{array}{l}\text { Estrada and Coates- } \\
\text { Estrada, } 1999\end{array}$ \\
\hline & & La Selva, Mexico & 20 & Stoner, 1996 \\
\hline & & La Selva, Mexico & 11 & Stoner, 1996 \\
\hline & & $\begin{array}{l}\text { Santa Rosa, } \\
\text { Costa Rica }\end{array}$ & 40 & $\begin{array}{l}\text { Chapman, 1987, } \\
1988\end{array}$ \\
\hline & & $\begin{array}{l}\text { Playo Escondida, } \\
\text { Mexico }\end{array}$ & 7 & Asensio et al., 2007 \\
\hline & $\begin{array}{l}\text { Alouatta } \\
\text { pigra }\end{array}$ & $\begin{array}{l}\text { Community } \\
\text { Baboon } \\
\text { Sanctuary, Belize }\end{array}$ & 5.9 & Silver et al., 1998 \\
\hline $\begin{array}{l}\text { Increase in time } \\
\text { spent inactive }\end{array}$ & $\begin{array}{l}\text { Alouatta } \\
\text { pigra }\end{array}$ & $\begin{array}{l}\text { Cockscomb } \\
\text { Basin Wildlife } \\
\text { Sanctuary, Belize }\end{array}$ & 6.5 & $\begin{array}{l}\text { Silver and Marsh, } \\
2003\end{array}$ \\
\hline
\end{tabular}

Source: Data compiled from behavioural and diet studies of at least nine months in duration to account for seasonality. This resulted in three studies for A. pigra and 13 for A. palliata. See reference list for full references of studies included. 
Taxonomic Tapestries

\section{Hurricane-to-coastline ratios}

In order to calculate the number of hurricanes in relation to length of coastline (a hurricane to coastline ratio) for A. pigra and A. palliata, species distribution maps based on Rylands and others (2006) and hurricane tracks obtained from the National Oceanic and Atmospheric Administration (NOAA) in digital format, were plotted in ArcGIS 10.1 (ESRI, 2012). Political boundary data of all Central American countries consisted of datasets from the Digital Chart of the World (Defence Mapping Agency, 1992). These datasets have a standard 1:1,000,000 scale and were used as the base for coastline measures. For the purpose of this study we chose to use a method that would be easily repeatable yet still provide a valid measure of coastline length with respect to the potential distance that tropical storms could cross. Coastline lengths for A. pigra and A. palliata ranges were calculated using the 'detailed hull' function in the extension XTools Pro 9.2 (Data East, 2012) in ArcGIS. The detailed hull function creates a 'contour' around outer points similar to that of a standard convex hull, except that it does include some concave angles when consecutive line segments fall below a certain length - the result of this detailed hull function is a 'finer scaled convex hull'. If the actual length of coastline was used, it would overestimate length due to undulations caused by major inlets and bays along the actual coastline. These are especially apparent along the coast of Belize.

The complete dataset of hurricane tracks included hurricanes from Category 1 to 5, tropical storms, and tropical depressions of all known and recorded storms from the years 1851 to 2007. Because hurricane strength often changes once hitting land, it was not possible to calculate a reasonable comparative measure of number of hurricanes by species range area. Thus we calculated a ratio of the number of hurricanes crossing the coastline for each of the species' range. Coastline measurements were clipped to create a measure for the two species ranges' separately. Hurricane track data were filtered so that two measures could be performed: (1) all tropical depressions, tropical storms, and hurricanes Category 1 to 5 ; (2) hurricanes only (all categories).

\section{Results}

\section{Forest patch characteristics of $A$. pigra in Belize}

We recorded a total of 83 visual and 110 vocal contacts of $A$. pigra within Belize and collected another 284 confirmations of presence from other reliable sources. All patches were sampled in lowland habitat and a chi square test for independence $(\mathrm{p}=0.05)$ found that $A$. pigra were more likely to be present in 
a patch classified as lowland broad-leaf moist and wet forest, and more likely to be absent from patches classified as agriculture, lowland savannah, shrubland, or wetland. The area-weighted mean elevation of all patches ranged between sea level and $222 \mathrm{~m}$ ASL with the highest confirmation of an A. pigra group at $700 \mathrm{~m}$ and the highest reported sighting of a group at $289 \mathrm{~m} \mathrm{ASL}$. When considering factors influencing the relative abundance of $A$. pigra, only the amount of edge was positively associated $(r=0.545 ; \mathrm{p}=0.006)$ accounting for $30 \%$ of the variation in relative abundance $\left(r^{2}=0.297\right)$.

We found a significant positive relationship between the number of settlements in a patch and the presence of $A$. pigra, with more settlements in present patches (1.19) than absent patches (0.14). There was also a significant relationship between $A$. pigra presence and patch size. Patches ranged in size from $0.13 \mathrm{~km}^{2}$ to over $1256 \mathrm{~km}^{2}$ with the largest patch occurring in the Rio Bravo and Gallon Jug region and the smallest patches $\left(<1.0 \mathrm{~km}^{2}\right)$ adjacent to the Belize River. We found present patches to be, on average, larger $\left(117.24 \mathrm{~km}^{2}\right)$ than absent patches $\left(27.29 \mathrm{~km}^{2}\right)$.

\section{Behavioural comparisons of $A$. pigra and $A$. palliata}

Our literature review found $A$. pigra to live in significantly smaller groups than A. palliata with $A$. pigra living in groups ranging from 5.9 to 9 individuals $(\overline{\mathrm{x}}=6.83, \mathrm{CV}=19.55)$ and $A$. palliata living in groups ranging from 4 to 59 individuals $(\overline{\mathrm{X}}=15.37, \mathrm{CV}=79.78)$. Group size in $A$. palliata was more variable, which may be due to the increased sample size for the comparatively well studied mantled howler or reflect group size constraints that may be present in A. pigra due to the stochastic nature of their environment.

When examining the relationship between fruit consumption and activity patterns we found no consistent differences within or between species in how populations adjust behaviour during periods of fruit shortage. Populations of A. pigra either decreased time spent travelling (from $9.52 \%$ to $5.45 \%$ ), increased time spent inactive (from $69 \%$ to $77 \%$ ) or did not adjust activity patterns in response to seasonal reductions in fruit intake (Behie and Pavelka, 2005; Silver et al., 1998; Pavelka and Knopff, 2004). While some groups of $A$. palliata also did not show changes in activity that correspond to fruit production, the most common response reported in the literature is an increase in either travel time (from 18.6\% to $35.8 \%$ in A. palliata in Nicaragua, Williams-Guillen, 2003) or ranging distance (from $114.05 \mathrm{~m}$ to $502.88 \mathrm{~m}$ for a population in Mexico, Estrada, 1984), which is a response that has never been reported for a population of $A$. pigra. 


\section{Severe weather events in the ranges of $A$. pigra and A. palliata}

The method described above resulted in a coastline length of $893 \mathrm{~km}$ for $A$. pigra and $1372 \mathrm{~km}$ for A. palliata. Since 1851, 118 Atlantic hurricanes, depressions or tropical storms have crossed into coastal regions populated by $A$. pigra, where only 40 have crossed into the range of $A$. palliata. There is a significantly higher storm to coastline ratio of 0.132 for $A$. pigra than the 0.0292 for $A$. palliata $\left(X^{2}\right.$ $=37.52, \mathrm{df}=1, \mathrm{p}<0.0001$ ) (Figure 4.1a). When considering hurricanes only, the difference is still evident. Many more hurricanes crossed the coastal regions of A. pigra $(\mathrm{N}=49)$ compared to A. palliata $(\mathrm{N}=19)$ (Figure $4.1 \mathrm{~b})$. The hurricane to coastline ratios ( 0.551 for $A$. pigra and 0.0138 for $A$. palliata) were significantly different $\left(\mathrm{X}^{2}=12.36, \mathrm{df}=1, \mathrm{p}=0.0004\right)$.

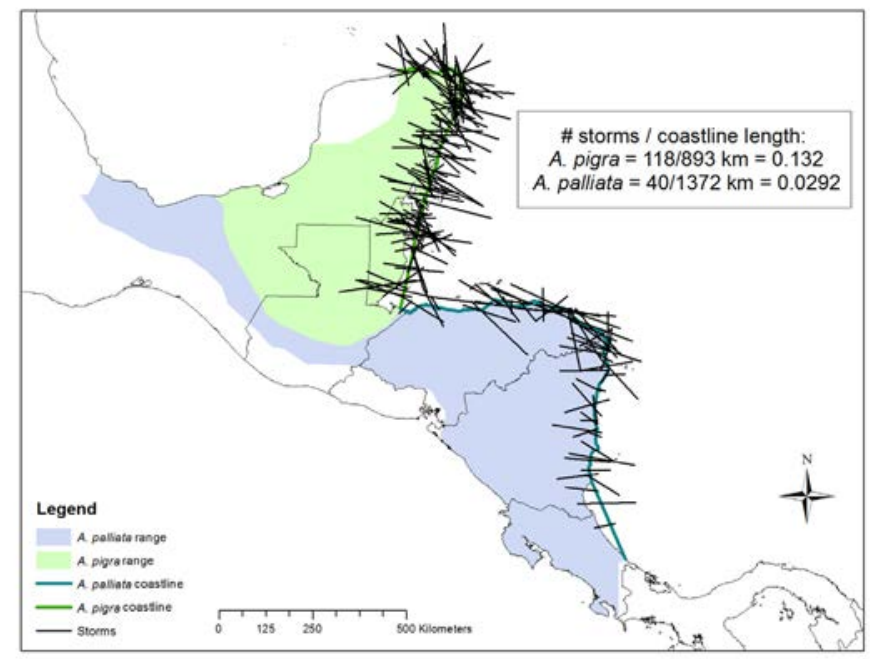

Figure 4.1a: Total number of storms that crossed through the ranges of Alouatta pigra and Alouatta palliata from 1851 to 2007.

Source: Data were obtained from the National Oceanic and Atmospheric Administration (NOAA) and plotted in ArcGIS 10.1 (ESRI, 2012). Political boundary data of all Central American countries consisted of datasets from the Digital Chart of the World (Defence Mapping Agency, 1992). These datasets have a standard 1:1,000,000 scale and were used as the base for coastline measures. 
4. Hurricanes and coastlines

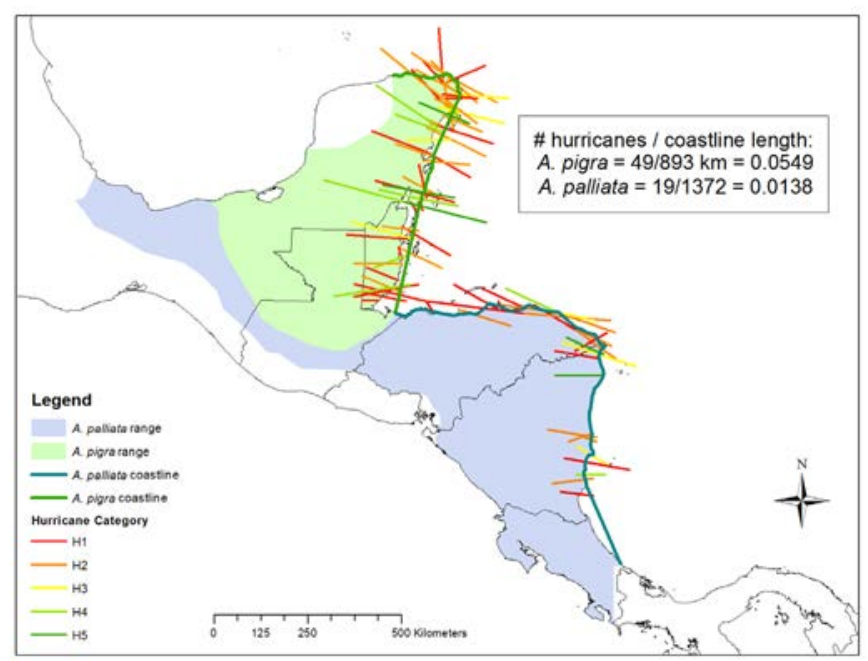

Figure 4.1b: Total number of hurricanes that crossed through the ranges of Alouatta pigra and Alouatta palliata from 1851 to 2007.

Source: Data were obtained from the National Oceanic and Atmospheric Administration (NOAA) and plotted in ArcGIS 10.1 (ESRI, 2012). Political boundary data of all Central American countries consisted of datasets from the Digital Chart of the World (Defence Mapping Agency, 1992). These datasets have a standard 1:1,000,000 scale and were used as the base for coastline measures.

\section{Discussion}

The evolutionary history of $A$. pigra and $A$. palliata in Mesoamerica is not entirely understood. Colonisation of Mesoamerica by South American species took place after the formation of a land bridge between the two regions approximately 3.5 million years ago (Ford, 2006), and genetic data suggest that the two Alouatta species diverged from one another close to 3.0 Mya (CoresOrtiz et al., 2007). Whether they colonised Mesoamerica before or after this speciation event, A. pigra is currently limited to a small geographic range in the Yucatan Peninsula compared to a relatively wide distribution of $A$. palliata. The aim of this paper was to investigate the potential role of environmental stochasticity in the geographic distribution and possibly speciation of $A$. pigra and $A$. palliata through: an examination of the forest characteristics that predict the presence of $A$. pigra; a comparison of the behavioural traits of $A$. pigra and $A$. palliata that might suggest an evolutionary history shaped by living in a stochastic environment; and finally a comparison of the prevalence of severe weather events, such as hurricanes, in the ranges of the two species. 
In terms of patch characteristics, we found a higher relative abundance of A. pigra in Belize in lowland broad-leaf moist and wet forest, in line with previous reports that $A$. pigra inhabit primarily lowland riverine coastal forests (Horwich and Johnson, 1986; Reid, 1997). The highest published densities reported for $A$. pigra have been at the Community Baboon Sanctuary (CBS) near the Belize River (257 ind/ $\mathrm{km}^{2}$, Ostro et al., 1999) and at Monkey River (102 ind/ $\mathrm{km}^{2}$, Pavelka, 2003). Seasonally flooded forests create localised disturbance which may improve soil quality and thus the quality of the howler food supply (Peres, 1997). We also found a significant positive relationship between both human settlements and patch size and the occurrence of A. pigra and between the amount of edge and the relative abundance of $A$. pigra. This suggests that $A$. pigra is tolerant of disturbance and may even prefer disturbed forest patches. One reason for such a preference may be that disturbed areas are colonised by fast growing pioneer species that invest little in chemical defence, thus produce leaves high in protein and low in fibre and secondary compounds (Coley, 1983). Folivores are able to take advantage of this and maintain a high quality diet despite an overall reduction in stem density. We found this to be the case following hurricane Iris in Monkey River where A. pigra shifted their leaf consumption to include up to $75 \%$ Cecropia peltata, which had the highest protein to fibre ratio and the third highest concentration of sugar of all ingested species (Behie et al., 2014).

Living in disturbed forest patches may improve the food supply for folivores in the long term, but immediately following a severe natural disaster there would be substantial reductions in the available food supply. Many trees regenerate new leaves immediately following a hurricane (Klinger, 2006; Zimmerman and Covich, 2007; Waide, 1991), while other food sources such as fruit or flowers take longer to return (Waide, 1991; Behie and Pavelka, 2005; Ratsimbazafy et al., 2002). After Hurricane Iris hit Monkey River there was a 52 per cent loss of major fruit trees and an 18 month absence in all fruit production forcing resident A. pigra groups to rely on a completely folivorous diet (Behie and Pavelka, 2005; Behie and Pavelka, in press). Following natural disturbances ring-tailed lemurs (Lemur catta; LaFleur and Gould, 2009; Ratsambazafy et al., 2002), ruffed lemurs (Varecia v. editorium; Ratzimbazafy, 2006) lion-tailed macaques (Macaca silenus; Menon and Poirer, 1996) and black howlers (Alouatta pigra; Behie and Pavelka, 2005) altered their diets to include plant parts and species not previously ingested, some of which were exotic to the region or were located outside of the regular forest habitat.

Such changes in food supply would be expected to result in demographic and behavioural changes to deal with an unpredictable and irregular food supply. One such mechanism to cope with this would be to reduce group size to deal with increased feeding competition. The average group size of black-and- 
white lemurs decreased from seven individuals before Cyclone Gretelle to 2.5 individuals after (Ratsimbazafy et al., 2002) and after wildfires moved through Borneo, the number of gibbon groups of more than five members significantly decreased, while the number of pairs increased (O'Brien et al., 2004). Group size in A. pigra in Monkey River following Hurricane Iris fell from 6.32 individuals before the storm to less than five in the first year following the storm. This suggests that animals exposed to severe disturbance adapt in the short term by reducing group size.

If exposed to severe environmental change on a regular basis, it stands to reason that group size may be constrained, placing upper limits on how many animals could live in a group without suffering the ill effects of increased competition at times of food scarcity. This was suggested by Wright (1999) who noted that lemur populations affected by frequent cyclones lived in smaller groups than groups not impacted by severe weather. In our comparison with A. palliata we found that $A$. pigra have significantly smaller and less variable group sizes than do A. palliata. Mean group size in A. palliata is 15.37 (Glander, 1978; Estrada, 1982, 1984; Chapman, 1987; Larose, 1996; Stoner, 1996; Estrada et al., 1999; Serio-Silva et al., 1999; Solano et al., 1999; Rodriguez-Luna, 2003; Williams Guillen, 2003; Munoz et al., 2006; Asensio et al., 2007; Dunn et al., 2009; Dunn et al., 2010) and mean group size in A. pigra is 6.83 (Silver et al., 1998; Silver and Marsh, 2003; Pavelka and Knopff, 2004; Pozo-Montuy and Serio-Silva, 2006). Considering the hurricane activity that occurs in the range of A. pigra, low group size could very well represent an adaptation to living in a stochastic environment. James et al. (1997) studied groups of $A$. pigra living at Bermudian Landing, Belize that were subjected to population declines from hurricanes in 1931, 1954 and 1978 as well as from a yellow fever epidemic which occurred in 1971. Each of these severe weather events caused a drastic decline in population numbers, and although they have recovered, the average group size in this region is only 4.6 individuals, lower than most other species of howlers. In 1999 this number increased to between four to 10 individuals, which although larger, is still smaller than other howler species (Ostro et al., 1999). A similar decline in group size was recorded in Monkey River following Hurricane Iris where group size remains smaller than before the storm even after more than a decade has passed.

We also found differences in activity patterns between A. pigra and A. palliata during periods of fruit scarcity. The prolonged fruit shortage following Hurricane Iris resulted in differences in activity levels between periods when fruit was not available (2002-mid-2004; mean fruit intake 4.93\%) and when it was available at close to pre-hurricane levels (mid-2004-2007; mean fruit intake $28.75 \%$ ). When fruit consumption was absent or very low, animals spent more time inactive and less time feeding and locomoting, probably minimising energy 
expenditure in response to low energy intake. An increase in time spent inactive and a reduction in time spent feeding has also been seen in howler monkeys following translocation to an unfamiliar environment (Silver and Marsh, 2003) and in lemurs in response to unpredictable resource availability and dramatic and prolonged shortages in fruit production in Madagascar (Wright, 1999). In lemurs this is also associated with a lower basal metabolic rate, which varies in response to changing fruit production, allowing them to maximise energy conservation (Pereira, 1993; Jolly, 1966). Increasing inactivity in the howlers at Monkey River in response to prolonged fruit shortage likely serves a similar function allowing howlers to conserve energy at times when higher quality resources (e.g. fruit) are not ingested. This however is not the response seen in A. palliata who have been reported to increase travel time (Williams-Guillen, 2003) or ranging distance (Estrada, 1984) when fruit is less available. This may be reflective of increased scramble competition in the larger groups of $A$. palliata, however, it may also be a result of $A$. palliata living in regions that show more predictability in fruit production with less need to conserve energy for long periods of food scarcity.

This successful dispersal of $A$. palliata may have resulted in their outcompeting A. pigra in most areas, pushing them up into their currently restricted range of southern Mexico, Belize and northern Guatemala (Ford, 2006). If this is true, and $A$. palliata were able to outcompete $A$. pigra and push them out of many regions, then the current range of $A$. pigra must represent areas that are not tolerated by A. palliata. There is no denying that exposure to hurricanes would create a selective pressure for animals living in hurricane belts, an idea that Colin himself agrees may have influenced speciation and/or current biogeographical distributions. Data presented here show that significantly more hurricanes pass into the range of $A$. pigra than the range of $A$. palliata. This may have been one reason why $A$. palliata did not extend their range into the hurricane belt of the Yucatan Peninsula, leaving A. pigra as the only Alouatta species to colonise the area. This is supported by the fact that $A$. pigra are commonly found in and may actually prefer disturbed forests and live in small groups who exhibit energy conservation strategies with regards to their activity budgets. Such adaptations to environmental stochasticity are also seen in lemurs regularly exposed to cyclones in Madagascar (Wright, 1999) suggesting they are necessary adaptive mechanisms to cope with high degrees of environmental perturbations. $A$. palliata may be less able to tolerate hurricane activity and unable to colonise the hurricane belt of the Yucatan Peninsula. While there may be other reasons contributing to the range separation of $A$. pigra and $A$. palliata, we argue that the role of hurricane activity cannot be ruled out as a possible explanation for the current biogeographical separation and potentially of speciation in these two species and potentially other species exposed to severe weather conditions. 
This is an idea rarely considered in theories of primate speciation or when considering current biogeographical ranges, but as severe weather events become more frequent and intense is one that warrants further investigation.

\section{Acknowledgements}

We wish to thank the Belize Government for granting us permission to conduct this research. The Monkey River Research Project could not be done without the assistance of guides and research assistants who aid in the collection of data and monitoring of the monkey population. Financial support for this research was received from The Natural Sciences and Engineering Council of Canada, The International Primatological Society, Sigma Xi, The Department of Anthropology, Faculty of Social Sciences and Graduate Studies at the University of Calgary. All data collection met the principles of the ethical treatment for animals and were approved by the Life and Environmental Sciences Animal Care Committee at the University of Calgary.

\section{References}

Asensio N, Cristobal-Azkarate J, Dias PAD, Vea JJ, Rodriguez-Luna E. 2007. Foraging habits of Alouatta palliata mexicana in three forest fragments. Folia Primatol 78:141-153.

Baumgarten A. 2006. The distribution and biogeography of Central American howling monkeys (Alouatta pigra and A. palliata). Masters Thesis, Louisiana State University.

Behie AM, Pavelka MSM. 2005. The short-term effect of Hurricane Iris on the diet and activity of black howlers (Alouatta pigra) in Monkey River, Belize. Folia Primatol 76:1-9.

Behie AM, Pavelka MSM. 2013. The interacting roles of nutrition, stress and parasitism in determining population density of howler monkeys living in a hurricane disturbed forest fragment. Chapter to be included in the book Primates infragments: Complexity and resilence. March LK, editor. Springer Press.

Behie AM, Kutz S, Pavelka SMS. 2014. Cascading effects of climate change: How do hurricane-damaged forests increase exposure to parasies. Biotropica. $46: 25-34$. 
Behie AM, Pavelka MSM. In press. Fruit as a key factor in howler monkey population density: Conservation implications. In: Kowalewski M, Garber PA, Cortes-Ortiz L, Urbani B, Youlatos D, editors. Howler monkeys: Examining the biology, adaptive radiation, and behavioral ecology of the most widely distributed genus of Neotropical primate. New York: Springer Press.

Chapman CA. 1987. Flexibility in diets of three Costa Rican primates. Folia Primatol 49:90-105.

Coley PD. 1983. Herbivory and defensive characteristics of tree species in a lowland tropical forest. Ecol Monographs 53(2):209-234.

Cortes-Oritz L, Bermingham E, Rico C, Rodriguez-Luna E, Sampaio I, RuizGarcia M. 2003. Molecular systematics and biogeography of the Neotropical monkey genus, Alouatta. Mol Phyl Evol 26:64-81.

Data East. 2012. XTools Pro for ArcGIS Desktop. 9.2. Data East, LLC.

Defense Mapping Agency. 1992. Digital Chart of the World. Fairfax, VA: Defense Mapping Agency.

Dunn JC, Asensio N, Arroyo-Rodriguez V, Schnitzer S, Cristobal-Azkarate J. 2009. The ranging costs of a fallback food: Liana consumption supplements diet but increases foraging effort in howler monkeys. Biotropica 43:612-618.

Dunn JC, Cristobal-Azkarate J, Vea JJ. 2010. Seasonal variations in the diet and feeding effort of two groups of howlers in different sized forest fragments. Int J Primatol 31:887-903.

Environmental Systems Resource Institute (ESRI). 2012. ArcGIS 10.1. Redlands, California: ESRI.

Estrada AR. 1982. Survey and census of howler monkeys (Alouatta palliata) in the rainforest 'Lox Tuxlas' Veracruz, Mexico. Am J Primatol 2:363-372.

Estrada A. 1984. Resource use by howler monkeys (Alouatta palliata) in the rainforest of 'Los Tuxlas', Veracruz, Mexico. Int J Primatol 5:105-131.

Estrada A, Anzures A, Coates-Estrada R. 1999. Tropical rainforest fragmentation, howler monkeys (Alouatta palliata), and dung beetles at Los Tuxlas, Mexico. Am J Primatol 48:253-262.

Ford SM. 2006. The biogeographic history of Mesoamerican primates. In: Estrada, A, Garber PA, Pavelka MSM, Luecke L, editors. New perspectives in the study of Mesoamerican primates: Distribution, ecology, behavior, and conservation. New York: Springer. pp. 81-120. 
Glander KE. 1978. Howling monkey feeding behavior and plant secondary compounds: A study of strategies. In: Montgomery GG, editor. The ecology of arboreal folivores. Washington, DC: Smithsonian Press. pp. 561-573.

Groves CP. 2001. Primate taxonomy. Washington, DC: Smithsonian Books.

Horwich RH, Johnson ED. 1986. Geographic distribution of the black howler (Alouatta pigra) in Central America. Primates 2:53-62.

James R, Leberg PL, Quattro JM, Vrijenhoek RC. 1997. Genetic diversity in black howler monkeys (Alouatta pigra). Am J Phys Anthropol 102:329-336.

Jolly A. 1966. Lemur behaviour: A Madagascar field study. Chicago: University of Chicago Press.

Klinger R. 2006. The interaction of disturbances and small mammal community dynamics in a lowland forest in Belize. J Anim Ecol 75:1227-1238.

LaFleur M, Gould L. 2009. Feeding outside the forest: The importance of crop raiding and an invasive weed in the diet of gallery forest ring-tailed lemurs (Lemur catta) following a cyclone at the Beza Mahafaly Special Reserve, Madagascar. Folia Primatol 80:233-246.

Larose F. 1996. Foraging strategies, group size and food competition in the mantled howler monkey, Alouatta pigra. PhD thesis, University of Alberta.

Menon S, Poirer FE. 1996. Lion-tailed macaques (Macaca silenus) in a disturbed forest fragment: Activity patterns and time budget. Int J Primatol 17:969985.

Milton K. 1980. The foraging strategy of howler monkeys: A study in primate economics. New York: Columbia University Press.

Milton K. 1981. Food choices and digestive strategies of two sympatric species. Amer Nat 117:496-505.

Munoz D, Estrada A, Naranjo E, Ochoa S. 2006. Foraging ecology of howler monkeys in a cacao (Theobroma cacao) plantation in Comalcalco, Mexico. Am J Primatol 68:127-142.

National Oceanic and Atmospheric Administration (NOAA). 2006. Historical North Atlantic and East-Central North Pacific tropical cyclone tracks, 18512005. www.csc.noaa.gov/hurricane_tracks (accessed September 2006).

O'Brien TG, Kinnaird MF, Nurcahyo A, Iqbal M, Rusmanto M. 2004. Abundance and distribution of sympatric gibbons in a threatened Sumatran rainforest. Int J Primatol 25:267-284. 
Taxonomic Tapestries

Ostro LET, Silver SC, Koontz FW, Young TP, Horwich RH. 1999. Ranging behavior of translocated and established groups of black howler monkeys Alouatta pigra in Belize, Central America. Biol Conserv 87:181-190.

Pavelka MSM. 2003. Population, group, and range size and structure in black howler monkeys $(A$. pigra) at Monkey River in southern Belize. Neotrop Primates 11:187-189.

Pavelka MSM, Behie AM. 2005. The effect of hurricane Iris on the food supply of black howlers (Alouatta pigra) in southern Belize. Biotropica 37:102-108.

Pavelka MSM, Knopff KH. 2004. Diet and activity in black howler monkeys (Alouatta pigra) in southern Belize: Does degree of frugivory influence activity level? Primates 45:105-111.

Pavelka MSM, McGoogan KC, Steffens TS. 2007. Population size and characteristics of Alouatta pigra before and after a major hurricane. Int $J$ Primatol 28:919-929.

Pereira ME. 1993. Seasonal adjustment of growth rate and adult body weight in ringtailed lemurs. In Kappeler PM, Ganzhorn JU, editors. Lemur social systems and their ecological basis. New York: Plenum Press. pp. 205-221.

Peres CA. 1997. Primate community structure at twenty western Amazonia flooded and un-flooded forests. J Trop Ecol 13:381-405.

Pozo-Montuy G, Serio-Silva JC. 2006. Comportamiento alimentario de monos aulladores negros (Alouatta pigra Lawrence, Cebidae) en habitat fragmentado en Balancan, Tabasco, Mexico. Acta Zoologica Mexicana 22:53-66.

Ratsimbazafy JH. 2006. Diet composition, foraging and feeding behavior in relation in habitat disturbance: Implications for the adaptability of ruffed lemurs (Varecia V. editorium) in Manombo forest, Madagascar. In: Gould L, Sauther ML, editors. Lemurs: Ecology and adaptation. New York: Springer Press. pp. 403-422.

Ratsimbazafy JH, Ramarosandratana HV, Zaonarivelo RJ. 2002. How do blackand-white ruffed lemurs survive in a highly disturbed habitat? Lemur News 7:7-10.

Reid FA. 1997. A field guide to the mammals of Central America and Southeast Mexico. New York: Oxford University Press.

Rodriguez-Luna E, Dominguez-Dominguez LE, Morales MJ, Martinez-Morales M. 2003. Foraging strategy changes in Alouatta palliata mexicana troop released on an island. In: Marsh LK, editor. Primates in fragments: Ecology and conservation. New York: Kluwer. 
Rylands AB, Groves CP, Mittermeier RA, Cortés-Ortíz L, Hines JJH. 2006. Taxonomy and distribution of Mesoamerican primates. In: Estrada A, Garber PA, Pavelka MSM, Luecke L, editors. New perspectives in the study of Mesoamerican primates: Distribution, ecology, behavior, and conservation. New York: Springer. pp. 29-81.

Serio-Silva JC, Hernandez-Salazar LT, Rico-Gray V. 1999. Nutritional composition of the diet of Alouatta palliata mexicana females in different reproductive states. Zoo Biol 18:507-513.

Sheddon-Gonzalez A, Rodriguez-Luna E. 2010. Responses of a translocated howler monkey Alouatta palliata group to new environmental conditions. Endang Sp Res 12:25-30.

Silver SC, Marsh LK. 2003. Dietary flexibility, behavioural plasticity, and survival in fragments: Lessons from translocated howlers. In: Marsh LK, editor. Primates in fragments: ecology and conservation. New York: Kluwer.

Silver SC, Ostro LET, Yeager CP, Horwich R. 1998. Feeding ecology of the black howler monkey (Alouatta pigra) in northern Belize. Am J Primatol 45:263279.

Smith JD. 1970. The systematic status of the black howler monkey, Alouatta pigra Lawrence. J Mammal 51:358-369.

Solano SJ, Martinez T, Estrada A, Coates-Estrada R. 1999. Uso de plantas como alimento por Alouatta palliata en un fragemento de selva en Los Tuxlas, Mexico. Neotrop Primates 7:8-11.

Stoner KE. 1996. Habitat selection and seasonal patterns of activity and foraging of mantled howling monkeys (Alouatta palliata) in north-eastern Costa Rica. Int J Primatol 17:1-30.

Waide RB. 1991. The effect of Hurricane Hugo on bird populations in the Luquillo Experimental Forest, Puerto Rico. Biotropica 23:475-480.

Williams-Guillen K. 2003. The behavioral ecology of mantled howling monkeys (Alouatta palliata) living in a Nicaraguan shade coffee plantation. Doctoral Dissertation, New York University.

Wright PC. 1999. Lemur traits and Madagascar ecology: Coping with an island environment. Am J Phys Anthropol 110:31-72.

Zimmerman JKH, Covich AP. 2007. Damage and recovery of riparian Sierra palms after hurricane Georges: Influence of topography and biotic characteristics. Biotropica 39:43-49. 
This text is taken from Taxonomic Tapestries: The Threads of Evolutionary, Behavioural and Conservation Research, edited by Alison M Behie and Marc F Oxenham, published 2015 by ANU Press, The Australian National University, Canberra, Australia. 